\title{
PERBANDINGAN HASIL PANEN PADI DIPENGARUHI RATA-RATA CURAH HUJAN ATAU IRIGASI DENGAN MODEL REGRESI NONLINIER KUBIK DIKABUPATEN SUKOHARJO
}

\author{
Dhian Dwi Hermawan 1); Bebas Widada ${ }^{2)}$; Retno Tri Vulandari ${ }^{3)}$ \\ 1) 2) Program Studi Sistem Informasi, STMIK Sinar Nusantara \\ 3) Program Studi Teknik Informatika, STMIK Sinar Nusantara \\ 1) dhiandwi8@gmail.com; ${ }^{2)}$ bbswdd@yahoo.com; ${ }^{3)}$ retnotv@sinus.ac.id
}

\begin{abstract}
The rice yields in Sukoharjo regency each year experience an unstable ups and downs. The absence of predicted rice yield prediction resulted in lack of information needed to increase rice production in Sukoharjo Regency. The purpose of this research is to apply Cubic Nonlinier Method to predict rice yield in Sukoharjo Regency by comparing irrigation model with rainfall average model to see the accuracy in predicting the rice harvest in Sukoharjo regency. The design method uses UML (Unified Model Language), a program created using vb net programming language and using sql server database, functionality testing using Black Box Test and validity testing using MSE and MAPE. The computed data is data of 2016. The results show prediction in 2017 with irrigation model has more accurate calculation result. The calculation of MSE and MAPE values manually and applying is the same ie75401808,23 and 3.01862E-14. The Cubic Nonlinear Method with irrigation model can be the initial solution to predict the rice harvest in Sukoharjo District and the output of the program is the prediction of rice harvest from the Cubic Nonlinietic Method method.
\end{abstract}

Keywords: Prediction, Nonlinear Regression, Cubic, Rice Harvest

\section{PENDAHULUAN}

Kabupaten Sukoharjo merupakan salah satu kabupaten penyangga pangan di Jawa Tengah. Ada berbagai macam tanaman pangan yang dihasilkan di Kabupaten Sukoharjo setiap tahunnya seperti tanaman padi, palawija, sayuran dan buah-buahan. Salah satu tanaman pangan yang terus dipacu pertumbuhannya adalah tanaman padi. Pada tahun 2015 produktivitas tanaman padi berhasil mencapai $75,26 \mathrm{kw} / \mathrm{ha}$, dengan produksi sebesar 374.535 ton dan luas panen sebesar 49.764 hektar. Kabupaten Sukoharjo terbagi menjadi 12 kecamatan yang terdiri dari 167 desa/kelurahan yang mempunyai lahan sawah sebesar 44,60\% (20.814 ha)

Hasil panen di Kabupaten Sukoharjo setiap tahunnya mengalami naik turun yang tidak stabil, sebagai upaya mengatasi agar tidak terjadi kenaikan harga yang ekstrim perlu adanya ramalan yang tepat dan akurat tentang hasil panen di Kabupaten Sukoharjo. Kurangnya saran prediksi hasil panen padi mengakibatkan kurangnya informasi yang dibutuhkan untuk meningkatkan produksi padi di Kabupaten Sukoharjo.

Dalam penelitian ini akan dilakukan prediksi hasil panen padi yang dipengaruhi oleh rata-rata curah hujan atau irigasi dengan metode regresi nonlinier kubik karena pola data fluktuatif mengikuti musim dan terdapat lebih dari 2 titik optimum [1]. Perhitungan Mean Square Error (MSE) dan Mean Absolute Percentage Error (MAPE) dengan nilai eror terkecil akan menjadi acuan untuk menghitung prediksi hasil panen padi [2]. Hasil yang diharapkan dari pembuatan sistem ini adalah aplikasi yang dapat memprediksi hasil panen padi di Kabupaten Sukoharjo. Dari aplikasi ini dapat diketahui gambaran prediksi hasil panen di tahun yang akan datang sehingga hasil tersebut dapat diketahui secara efektif yang dapat digunakan sebagai acuan untuk mengendalikan harga dan stok panen padi di Kabupaten Sukoharjo

\section{TINJAUAN PUSTAKA}

Dalam penelitian prediksi luas panen dan produksi padi dengan menggunakan metode adaptive neuro-fuzzy inference system (ANFIS) di Kabupaten Banyumas. Berdasarkan penelitian tersebut dapat disimpulkan, luas panen dan produksi padi dapat digunakan untuk peramalan produksi padi pada tahun selanjutnya di Kabupaten Banyumas [3]. Penelitian lain mengenai produksi panen menggunakan dua variabel perhitungan yaitu curah hujan dan hama pada tanaman padi. Penelitian tersebut di hitung menggunakan metode Least Square dengan 
hasil prediksi yang memiliki selisih yang tidak terpaut jauh dari data panen asli [4]. Hasil panen padi dipengaruhi oleh tiga faktor yaitu faktor luas lahan, irigasi dan tenaga kerja [5].

\section{METODE PENELITIAN}

\subsection{Penentuan Metode dan Variabel}

Ada berbagai metode penelitian dengan variabel yang berbeda-beda yang dapat digunakan dalam perhitungan prediksi hasil panen padi, seperti metode Trend Least Square, GARCH, Moving Average, Regresi Linier [6] dan Nonlinier [7]. Dan berbagai variabel perhitungan seperti luas lahan pertanian, letak wilayah, ketinggian tanah, pupuk dan lain sebagainya. Dalam penelitian ini variabel yang digunakan adalah irigasi dan rata-rata curah hujan, sedangkan metode prediksinya menggunakan metode Nonlinier Kubik. Metode tersebut digunakan karena hubungan antara variabel bebas dan terikat tidak linier. Tidak linier yang dimaksud adalah laju perubahan variabel terikat akibat laju perubahan variabel bebas tidak konstan untuk nilai variabel bebas tertentu. Oleh karena itu variabel irigasi dan rata-rata curah hujan dipilih untuk menghitung prediksi hasil panen padi, karena semakin tinggi rata-rata curah hujan atau semakin lebarnya irigasi belum tentu membuat hasil panen padi menjadi meningkat.

Tahap analisa dan perancangan sistem menentukan rancangan sistem yang akan dibuat, berdasarkan desain yang diusulkan dan analisis sistem yang telah dilakukan.

\subsection{Sumber Data Penelitian}

Data yang digunakan dalam penelitian tentang prediksi hasil panen padi adalah data rata-rata curah hujan dan irigasi dan hasil panen padi yang diperoleh dari Dinas Pertanian Kabupaten Sukoharjo.

\subsection{Pengembangan Sistem}

Pengembangan sistem metode yang digunakan adalah metode waterfall. Metode waterfall memiliki beberapa tahapan yang berurut yaitu: requirement (analisis kebutuhan), design system (desain sistem), coding (pengkodean) \&testing (pengujian), dan pemeliharaan.

\subsection{Perancangan Sistem}

Perancangan sistem menggunakan UML (Unified Model Language). UML merupakan bahasa visual untuk pemodelan dan komunikasi mengenai sebuah sistem dengan menggunakan diagram dan teks-teks pendukung untuk menspesifikasikan, menggambarkan, membangun, dan dokumentasi dari sistem perangkat lunak 8 . UML terdiri dari 4 macam diagram, yaitu Use Case Diagram, Activity Diagram, Class Diagram, dan Sequence Diagram.

\subsection{Flowchart Aplikasi}

Flowchart dalam pembuatan aplikasi prediksi hasil panen menggunakan metode regresi nonlinier kubik.

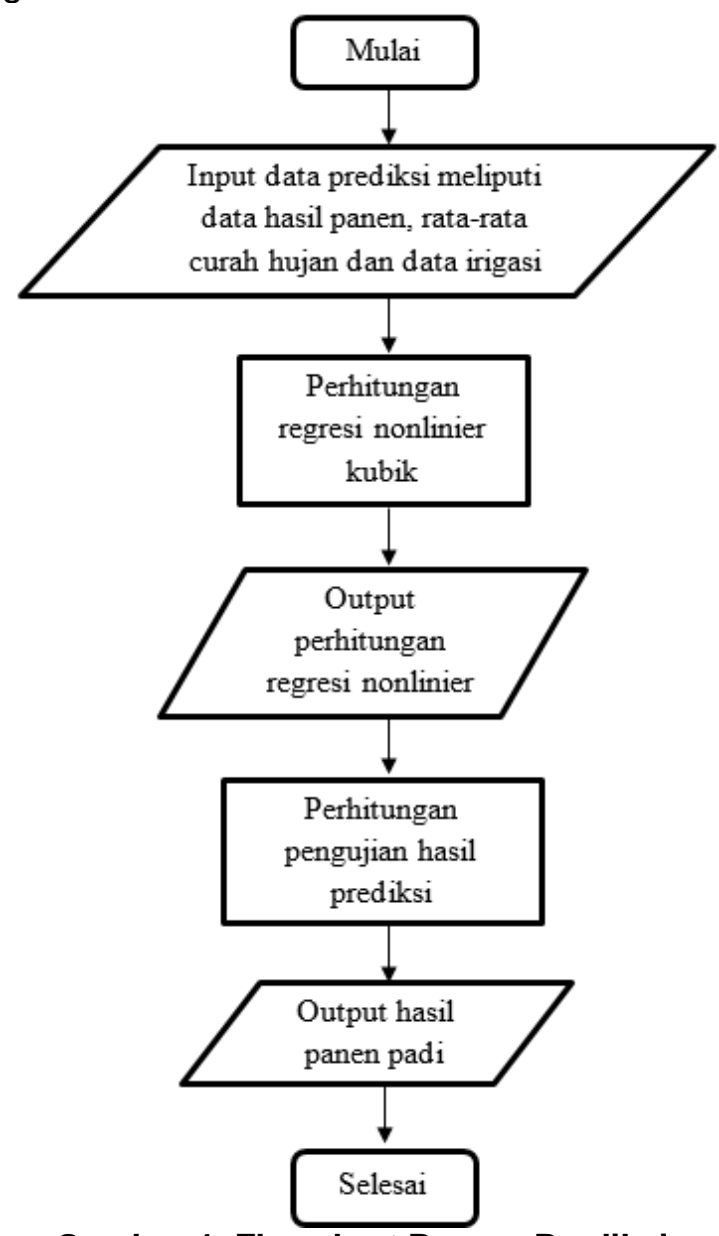

Gambar 1. Flowchart Proses Prediksi

Metode penelitian merupakan prosedur dan teknik penelitian. Antara satu penelitian dan penelitian lain, prosedur dan tekniknya akan berbeda. Kalau tidak berbeda berarti penelitian itu hanya mengulang penelitian yang telah ada sebelumnya.

\section{HASIL DAN PEMBAHASAN}

Tahap pembahasan berupa perhitungan dan perancangan sistem yang akan dibuat.

\subsection{Perhitungan Manual}

Untuk menghitung nilai $b_{0}, b_{1}, b_{2}, b_{3}$ dapat dilakukan dengan memasukkan $Z_{1}, Z_{2}$, $Z_{3}$ ke persamaan matrik. Dengan mengacu data mentah rata-rata curah hujan dan irigasi pada Tabel 1, maka diperoleh estimasi parameter persamaan regresi nonlinier. 
Tabel 1. Data Rata-rata Curah Hujan dan Irigasi

\begin{tabular}{|c|l|c|c|}
\hline No & \multicolumn{1}{|c|}{ Kec } & $\begin{array}{c}\text { Rata-rata } \\
\text { Curah Hujan } \\
(\mathrm{mm})\end{array}$ & $\begin{array}{c}\text { Irigasi } \\
\text { (ha) }\end{array}$ \\
\hline 1 & Polokarto & 17,25 & 2362 \\
\hline 2 & Tawangsari & 13,17 & 2169 \\
\hline 3 & Bendosari & 13,17 & 1484 \\
\hline 4 & Weru & 12,75 & 1341 \\
\hline 5 & Mojolaban & 12,67 & 1341 \\
\hline 6 & Grogol & 11,83 & 1234 \\
\hline 7 & Gatak & 11,67 & 1209 \\
\hline 8 & Baki & 11,33 & 1116 \\
\hline 9 & Kartasura & 10,25 & 1082 \\
\hline 10 & Sukoharjo & 9,92 & 587 \\
\hline 11 & Bulu & 9,58 & 471 \\
\hline 12 & Nguter & 9 & 395 \\
\hline
\end{tabular}

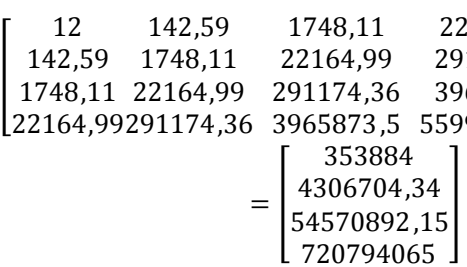

Dari matriks tersebut menghasilkan nilai $b_{0}$, $b_{1}, b_{2}, b_{3}$ sebagi berikut

$$
\left[\begin{array}{c}
1818788,137 \\
-431862,2277 \\
33691,47981 \\
-846,893748
\end{array}\right]=\left[\begin{array}{l}
b_{0} \\
b_{1} \\
b_{2} \\
b_{3}
\end{array}\right]
$$

Nilai b yang sudah di temukan dapat digunakan untuk menghitung prediksi hasil panen padi berdasarkan rata-rata curah hujan dengan perhitungan [8]. Berikut hasil dari perhitungan ditampilkan dalam Tabel 2

$$
Y=b_{0}+b_{1} Z_{1}+b_{2} Z_{2}+b_{3} Z_{3} .
$$

Dengan cara perhitungan yang sama,berikut hasil dalam mencari nilai $b_{0}, b_{1}$, $\mathrm{b}_{2}, \mathrm{~b}_{3}$ dengan data irigasi.

$$
\left[\begin{array}{c}
-4845,266533 \\
47,84285097 \\
-0,013722152 \\
8,23129 \mathrm{E}-07
\end{array}\right]=\left[\begin{array}{l}
b_{0} \\
b_{1} \\
b_{2} \\
b_{3}
\end{array}\right]
$$

Perbandingan hasil prediksi panen padi dengan rata-rata curah hujan dan irigasi dalam Tabel 2.

Untuk nilai MAPE yang didapatkan dengan model irigasi sebesar 3,01862E-14 dan model curah hujan sebesar 3,86565E-12. Dari kedua perhitungan diatas dapat diketahui penggunaan model irigasi sebagai perhitungan prediksi hasil panen pada tahun 2017 akan lebih akurat dengan nilai MSE yang lebih kecil sebesar 75401808,23 dan nilai MAPE sebesar 3,01862E-14.

Tabel 2. Hasil Panen Padi

\begin{tabular}{|c|l|c|c|c|c|c|}
\hline \multirow{2}{*}{ No } & \multirow{2}{*}{ Kecamatan } & \multirow{2}{*}{$\begin{array}{c}\text { Hasil } \\
\text { Panen } \\
\text { Padi }(\mathrm{y})\end{array}$} & \multicolumn{2}{|c|}{$\begin{array}{c}\text { Prediksi Berdasarkan Rata- } \\
\text { Rata Curah Hujan }\end{array}$} & \multicolumn{2}{c|}{$\begin{array}{c}\text { Perhitungan Berdasarkan } \\
\text { Irigasi }\end{array}$} \\
\cline { 5 - 8 } & & & $(\mathrm{x})$ & $(\hat{\mathrm{y}}=\mathrm{x}-\mathrm{y})$ & $(\mathrm{z})$ & $(\hat{\mathrm{y}}=\mathrm{z}-\mathrm{y})$ \\
\hline 1 & Weru & 29623 & 34206,83064 & 4583,830642 & 31898,52283 & $2275,522835^{\star}$ \\
\hline 2 & Bulu & 16867 & 28977,74518 & 12110,74518 & 18676,74668 & $1809,746676^{*}$ \\
\hline 3 & Tawangsari & 31031 & 40327,09345 & 9296,093452 & 38623,9411 & $7592,9411^{*}$ \\
\hline 4 & Sukoharjo & 40947 & 23483,02822 & $-17463,97178$ & 42446,79731 & $1499,797307^{*}$ \\
\hline 5 & Nguter & 46754 & 43720,49528 & $-3033,504719^{*}$ & 36620,68358 & $-10133,3164$ \\
\hline 6 & Bendosari & 43990 & 40327,09345 & $-3662,906548^{*}$ & 34844,04898 & $-9145,95102$ \\
\hline 7 & Polokarto & 47556 & 47419,81773 & $-136,1822661^{*}$ & 32601,10998 & $-14954,89$ \\
\hline 8 & Mojolaban & 17023 & 33025,17698 & $-12611,82302$ & 42768,54537 & $-2868,45463^{*}$ \\
\hline 9 & Grogol & 20872 & 22851,66815 & 5828,668155 & 11962,39024 & $-5060,60976^{*}$ \\
\hline 10 & Baki & 24986 & 18984,23143 & $-1887,768568^{*}$ & 34967,68418 & 14095,68418 \\
\hline 11 & Gatak & 24986 & 21328,91274 & $-3657,087258^{*}$ & 34393,94292 & 9407,942921 \\
\hline 12 & Kartasura & 9249 & 19882,90671 & 10633,90671 & 14730,58683 & $5481,5868227^{*}$ \\
\hline \hline
\end{tabular}

\subsection{Penerapan Aplikasi}

Untuk mengembangkan sistem dibuat user interface. Terdapat lima form dalam aplikasi prediksi panen padi [9]. Yaitu Tampilan Awal, Tampilan Input Data, Tampilan Perhitungan $b_{0}, b_{1}, b_{2}, b_{3}$, Tampilan Perhitungan Prediksi dan Form Nilai Error MSE [10].

\subsection{Pengujian Black Box}

Black Box Testing adalah uji coba yang dilakukan pada tampilan software, dan digunakan untuk mendemostrasikan fungsi software yang dioperasikan, apakah input diterima dengan benar, dan output yang dihasilkan benar[11].

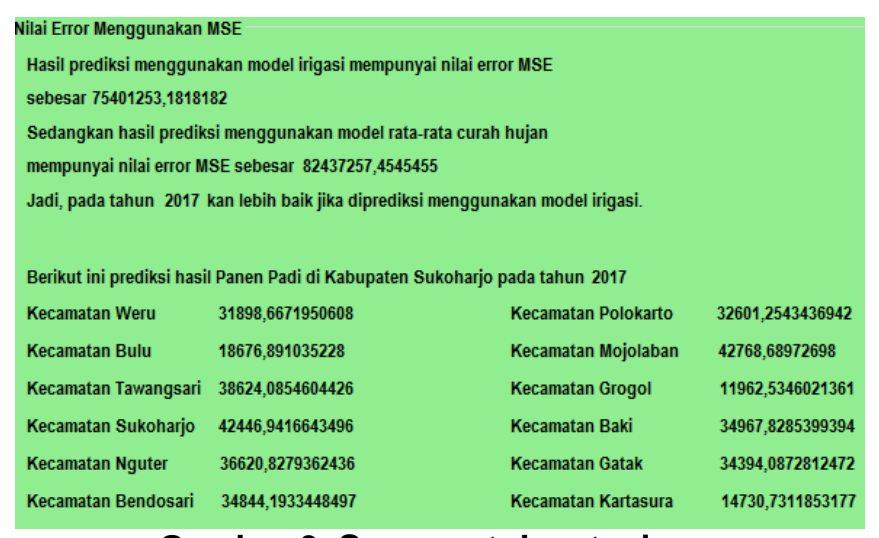

Gambar 3. Saran untuk petani

Jika pengguna sudah menghitung hasil prediksi maka data akan tampil pada form Nilai Error seperti pada gambar 12.Serta akan muncul saran untuk para petani pada masingmasing daerah yg mengalami peningkatan 
maupun penurunan hasil panen padi seperti pada Gambar 2 dan Gambar 3.

\subsection{Pengujian Validitas}

Dalam pengujian validitas dilakukan dengan membandingkan Mean Squared Error (MSE) dan Mean Absolute Percent Error (MAPE) secara manual dengan nilai irigasi dan nilai rata-rata curah. Untuk perhitungan ini data yang digunakan adalah data irigasi dan rata-rata curah tahun 2016. Selain menghitung MSE dan MAPE pengujian validitas juga membandingkan hasil perhitungan aplikasi dengan manual. Selisih data aktual hasil panen padi dan prediksi hasil panen padi sangat dibutuhkan untuk menghitung nilai MSE dan MAPE.

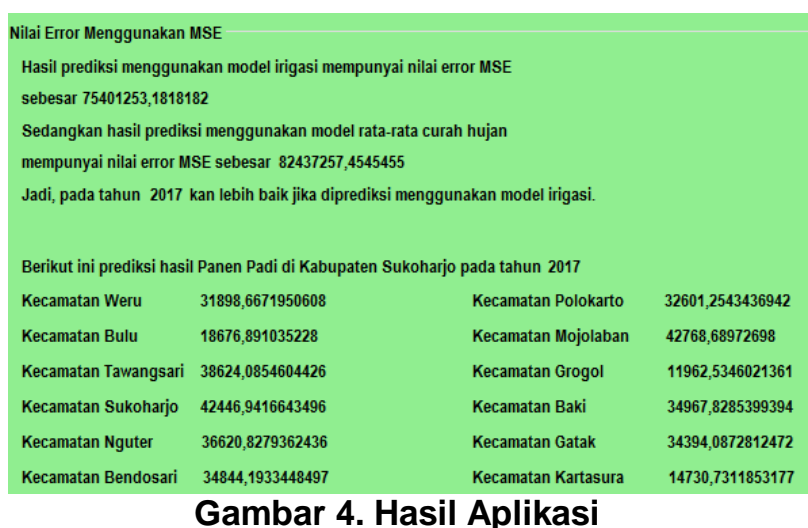

Dari kedua perhitungan error tersebut dapat diketahui penggunaan model irigasi sebagai perhitungan prediksi hasil panen padi pada tahun 2017 akan lebih akurat. Dengan nilai MSE yang lebih kecil sebesar 75401808,23 dan nilai MAPE sebesar 3,01862E-14. Selain itu antara hasil perhitungan manual dengan hasil perhitungan aplikasi memiliki hasil yang sama seperti yang ditunjukkan pada Gambar 4.

\section{PENUTUP}

\subsection{Kesimpulan}

Berdasarkan penelitian yang telah dilakukan maka dapat disimpulkan sebagai berikut:

1. Untuk mencari hasil prediksi hasil panen yang akurat dilakukan dengan mencari nilai-nilai MSE yang terkecil dengan membandingkan nilai irigasi dan rata-rata curah hujan yang berbeda. Hasil yang diperoleh menunujukkan bahwa dengan nilai irigasi menghasilkan nilai MSE yang paling kecil sehingga ramalan yang dihasilkan lebih akurat.
2. Hasil dari perhitungan manual maupun perhitungan aplikasi metode Nonlinier Kubik model irigasi menghasilkan nilai MSE sebesar 75401808,23 dan nilai MAPE sebesar 3,01862E-14 . Besarnya nilai MAPE yang dihasil termasuk nilai MAPE yang kecil karena kurang dari 10, sehingga metode ini cocok digunakan untuk prediksi hasil panen padi.

3. Aplikasi yang dibuat dengan bahasa pemrograman $\mathrm{vb}$ net menggunakan perhitungan Nonlinier Kubik dengan membandingkan hasil prediksi irigasi dan rata-rata curah hujan.

\subsection{Saran}

Adapun saran yang dapat diberikan dalam hasil penelitian ini untuk penelitian selanjutnya adalah sebagai berikut :

1. Pada penelitian selanjutnya dapat mencoba menggunakan variabel dan metode yang berbeda dan dengan jumlah data yang lebih besar, sehingga nilai data selanjutnya yang dihasilkan dapat menghasilkan tingkat eror yang lebih kecil.

2. Penelitian ini disarankan dapat menjadi bahan referensi yang dipergunakan dan dikembangkan untuk penelitian selanjutnya.

3. Program yang dibuat masih statis yang hanya dapat membandingan dua macam variabel saja. Diperlukan pengembangan program untuk penelitian selanjutnya agar memudahkan user ke depannya.

4. Hasil dari program yang dibuat menunjukkan prediksi dengan model irigasi lebih akurat, hal ini sejalan dengan daerah penelitian yang sudah mempunyai sistem irigasi yang baik. Pada penelitian kedepannya diharapkan tidak hanya membandingkan antara rata-rata curah hujan dan irigasi di satu daerah saja, akan tetapi bisa membandingkan antara satu daerah dengan daerah lain yang menggunakan tadah hujan.

\section{DAFTAR PUSTAKA}

[1] E. Purwantini and R. Susetyoko, "Pemodelan Temperatur Ruang Menggunakan Regresi Non Linier Berdasarkan Hasil Estimasi FEM 3-D Linier," 2016.

[2] A. Suparyanto, T. Wiradarya, and dan H. $\mathrm{H}$ Martojo, "Analisis Pertumbuhan NonLinier Domba Lokal Sumatera Dan Persilangannya," J. IImu Ternak dan Vet., 
vol. 6, no. 4, pp. 259-265, 2001.

[3] W. Suparta and K. M. Alhasa, "Modeling of Tropospheric Delays Using ANFIS," no. 2009, pp. 5-19, 2016.

[4] A. F. Nurudin, "Aplikasi Prediksi Hasil Panen Padi Dengan Metode Least Square," Kediri, 2015.

[5] H. R. T. Bhuana, "Model Prediksi Produksi Panen Komoditas Padi Menggunakan Metode Regresi Linier Berganda," Salatiga, 2012.

[6] Muldianto, "Penerapan Algoritma Regresi Linier Berganda untuk Prediksi Kebutuhan Air PDAM Kabupaten Sukoharjo," Surakarta, 2017.

[7] R. T. Vulandari, "Pengaruh Beban Kerja Individu, Beban Kerja Organisasi, dan Kepemimpinan terhadap Kinerja Karyawan," J. Math. Educ. Sci. Technol., vol. 1, no. 2, pp. 106-121, 2016.

[8] H. Budiadi, "Analisa Dampak Kepemimpinan Karismatik Terhadap Kinerja Karyawan di Pemerintah Daerah Kabupaten Sukoharjo," J. IIm. SINUS, pp. 67-79.

[9] Anisa Romandoni, "Penerapan Metode Regresi Linier Berganda Untuk Prediksi Hasil Panen Jagung," Surakarta.

[10] S. H. F. Widi Setyoko, Muhammad Hasbi and M. Di, "Sistem Pendukung Keputusan Prediksi Kualitas Kredit Calon Debitur menggunakan MJetode KNN," J. TIKomSiN, vol. Vol 4, No, pp. 61-68, 2016.

[11] R. T. Vulandari, Data Mining: Teori dan Aplikasi Rapidminer. Yogyakarta: CV. Gava Media, 2017. 